\title{
Estética Siglo XX
}

Elisa Alejandra Martínez Camacho

Alumna del $V$ Semestre de la

Licenciatura en Artes Plásticas

\section{Introducción}

A lo largo de la historia la estética se le ha entendido como la reflexión del arte y de lo bello, y aunque no se le conocía como estética desde un principio, siempre se ha tratado sobre esto, y ha ido evolucionando con el tiempo y con la propia forma de pensar de las personas.

Según Victor Basch "El estético es algo distinto de un espectador sensible o de una artista inspirado. Su función propia consiste en comprender y hacer comprender lo que escapa a la confusión y al desorden del goce y a la ebriedad de la creación" (Bayer, 1965, pág. 399).

Desde la antigüedad el ser humano ha buscado representar o plasmar cosas que lo rodean, y si bien no lo ha hecho de manera consciente, como podría ser el caso de las pinturas rupestres, el solo hecho de usar la limitada paleta de colores de que disponía en su tiempo nos habla de una búsqueda inherente de la representación del mundo, de su mundo o el cómo esas personas de ese determinado tiempo lo veían y lo interpretaban de la manera más realista posible: la búsqueda de la mímesis. Aunque en este periodo no se puede hablar de una búsqueda consciente de belleza, no podemos negar que las obras del ser humano primitivo poseen una belleza propia. Pasando por cada periodo en la historia nos encontramos con una definición de belleza diferente, una idea diferente de lo que es o no es estéti-

co y esto se ve reflejado en el arte de cada época. Si bien la idea de lo que es bello fue cambiando, no es sino hasta el siglo XX cuando hablamos de una estética completamente nueva.
Si observamos la evolución de la estética a través de los diferentes periodos artísticos vemos un camino marcado, desde el renacimiento donde la belleza se lograba a través de las matemáticas con el uso de los cánones y la perspectiva; desde el barroco donde todo era drama, luz y contraste, expresividad y además vemos la aparición de los sentimientos y emociones en la obra, que es algo que continúa hasta el romanticismo donde las pasiones ya no se representan en gestos sino en un ambiente completo.

Vemos pinturas de tormen-

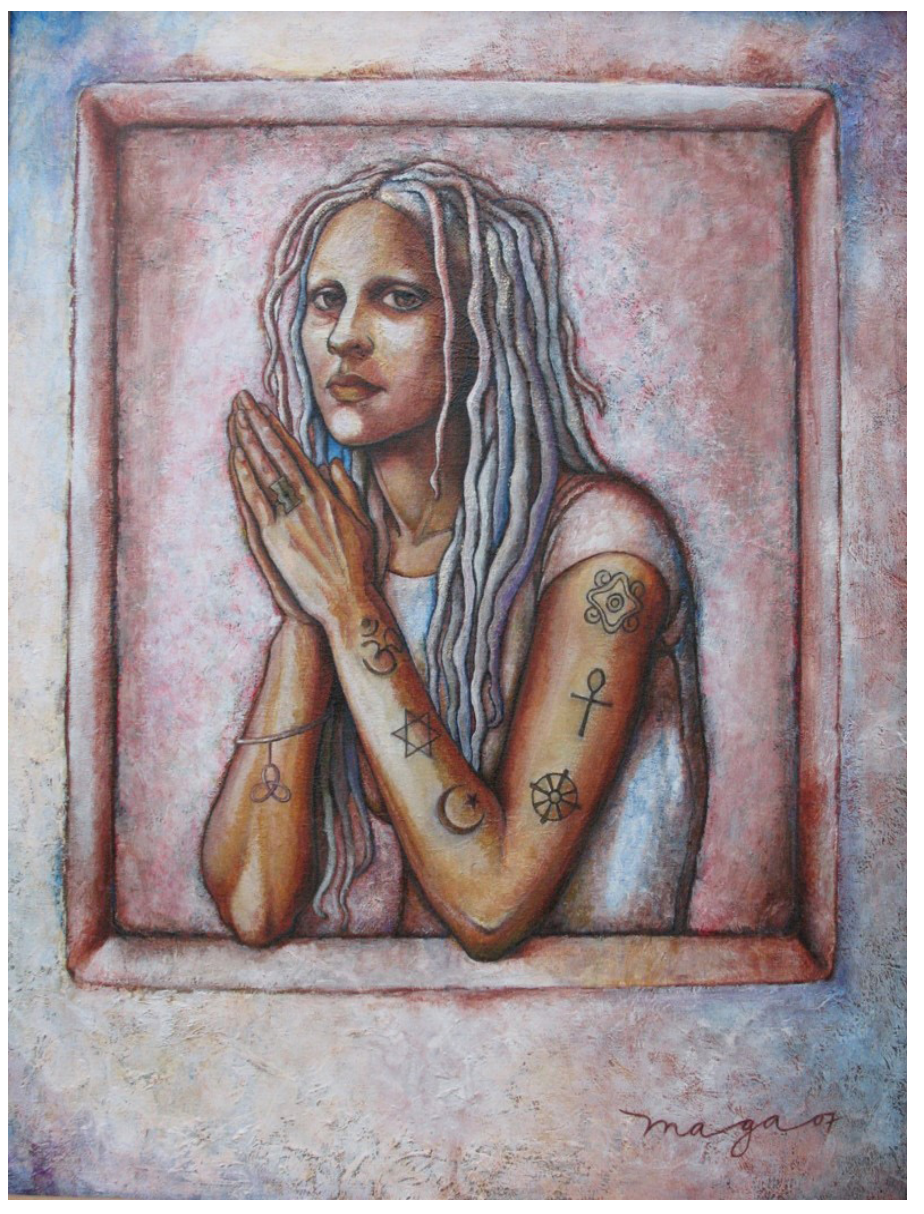

Autor: Ana Marcela García Título: ECLECTICIA

Técnica: Acrílico sobre lienzo Medidas: $80 \times 100 \mathrm{~cm}$. tas que se piensa evocaban lo divino o por el contrario a lo no divino, o a multitudes luchando por un ideal; la belleza del romanticismo está en el sentir individual de cada hombre y en su relación con la naturaleza, en la que encuentra reflejado su sentir. A partir del Impresionismo la idea de lo bello sufre un cambio más dramático, se sigue por la misma corriente de los sentimientos, el arte ya no busca relatar algo acontecido o dar lecciones como fue en un principio, ahora el artista es quien habla a través de su creación y lo que busca es plasmar una sensación de un momento vivido y para ello la línea y el dibujo ya no son suficientes: el color gana terreno y la mancha es la nueva técnica. Es aquí donde la estética se transforma para entender este nuevo arte y esta nueva idea de lo que es

bello.

Antes de empezar a hablar de autores hay que entender el lenguaje del arte. Según Goodman el arte nos da nuevas formas de entender el mundo antiguo, nos permite recrear 
la realidad; el autor dice que cada arte tiene un lenguaje distinto y un sistema de simbolización propio. En cuanto al arte plástico nos habla de que una obra puede denotar algo, esto quiere decir que hace referencia o representa algo mediante una imagen que no imita la realidad; y que también ejemplifica y expresa, es decir que posee una cualidad o característica que es propia de la obra y esto lo explica con un ejemplo usando La Guernica de Picasso, que denota el tema de un bombardeo y ejemplifica el gris, que es también un predicado para expresar tristeza.

Sánchez Ortega habla sobre la fenomenología y hace referencia a la obra pictórica como una ventana a la irrealidad $y$ dice que el arte no imita la realidad, sino que la simboliza. A partir del siglo XIX y siguiendo con el tema de la pintura, con este nuevo movimiento impresionista el arte se populariza; todos pueden entender estas escenas coloridas que son simples capturas de una vida cotidiana. El simbolismo pierde presencia y la pintura ahora es sencilla y accesible. A partir de esta ruptura completa con la técnica clásica (que ya podíamos ver en algunos románticos), se experimenta con los materiales, las formas, los colores y efectos,

lo que nos lleva a los movimientos post-impresionistas y sus autores como serían Van Gogh y Cézanne, los padres de las futuras vanguardias del siglo XX.

Comenzando el estudio de la estética del siglo XX en Francia, en el texto de Bayer nos encontramos con la guerra, que es lo que definirá este siglo en todos sus aspectos. Bayer distingue dos periodos, el primero llega a la guerra de 1939- 1940 y el segundo parte del momento de la Liberación de 1945. El primer periodo es racionalista, equilibrado, con un método rígido y lúcido. En el segundo "[...] la rectitud de las disciplinas cede su lugar a una especie de confusión de los géneros y las doctrinas" (Bayer, 1965, pág. 399). Esto es muy claro en todo el arte que vemos durante el siglo XX, es como si todos tuvieran algo que decir y buscaran la forma más impactante o novedosa para hacerlo. Encontramos en este periodo muchos autores que hablan de estética con diferentes opiniones. Para Victor Bach por ejemplo, la estética es una ciencia autónoma, con sus métodos propios que debe enseñarse. Y la actitud estética es un comportamiento propio del ser humano, un sentimiento de simpatía por el universo que nos permite tener sentimientos en los objetos mismos a partir de una actitud psíquica de simbolización, una simbiosis afectiva entre el Yo y el Universo. Bach nos habla de una simpatía simbólica. Su opinión plantea de que estamos conectados con todo lo que existe y que esta constante búsqueda de lo bello es algo que está en nosotros como seres humanos.

Valeriano Bozal nos habla de Baudeliere y de la herencia del romanticismo en el arte moderno, con sus artistas rechazados que buscaban la verdad en la pintura y se negaban a copiar a los clásicos. Según Baudelaire, el mundo urbano había sustituido la belleza natural por la artificial. Y él mismo habla del color como un factor decisivo del lenguaje pictórico para los románticos, algo que continuará en las siguientes corrientes (Bozal, 1999, pág. 17).

Sin embargo la naturaleza estaba presente en las obras modernas, como dice Bozal en su texto..."la búsqueda de ese contacto directo con la naturaleza [...] no se abandona, se reinventa una vez tras otra" (1999, pág. 17). Y esto lo podemos ver en las obras de Matisse y de Coubert, sólo que ahora la naturaleza es la vida diaria y lo que el artista busca es la verdad. Y esta búsqueda de la verdad no puede darse de la misma manera que antes, no con las nuevas formas de ver las cosas, de lo que hablo es del enfoque de la percepción visual, del "ojo del artista", de la retina que es propia del artista y le permite ver el mundo sin intermediarios. Ahora cada uno pinta lo que ve y cómo lo ve. Ya no se pinta un mundo idealizado, y los elementos que se utilizaban para componerlo ahora quedan en manos de un artista nuevo que no busca plasmar la belleza como debe ser, sino lo que es para quien lo ve, que incluso no busca la belleza. El artista del siglo XX crea mundos propios. Es así como se empiezan a plantear nuevos problemas y a buscarse soluciones innovadoras y los elementos que antes solo servían como base para plasmar la obra ahora cobraban un nuevo sentido: "replantean la posibilidad misma de la representación pictórica" (Bozal, 1999, pág. 19). Con estas nuevas formas de resolver la pintura y en una época sin academicismos, bombardeada por tantos cambios y movimientos en todos sentidos, surgen las vanguardias junto con muchas y variadas ideas de lo que es la estética.

En la estética francesa también encontramos autores como el ya mencionado Victor Bach, Henri Focillon que decía que los materiales y las técnicas definen el estilo y hablaba de la vida de las formas; Marc Jacobs que se oponía al naturalismo y al realismo; a Alain que decía que no había que pensar antes de crear, que la idea surgía del objeto o material. Vemos a Válery y su doctrina que dice negar la existencia de la estética al mismo tiempo dice que ésta solo debe servir para ayudar a disfrutar más una obra o ayudarla a que sea mejor; está también el pensamiento de André Bretón y su manifiesto surrealista en el que se 
encuentra la definición clásica del surrealismo y del automatismo psíquico. A partir del periodo de posguerra la estética, la filosofía y la psicología comienzan a mezclarse y encontramos pensamientos como los de René Huyghe que dice que en la obra de arte está nuestra personalidad, nuestro Yo y el "no-Yo", refiriéndose al universo que vivimos que es exterior a nosotros y es un vínculo entre el Yo y el espectador. Habla de la obra de arte como una imagen símbolo y una expresión de una realidad mental (Bayer, 1965, pág. 412). Esta teoría me pareció relacionada a la de Victor Bach, y me gusta por la misma razón, le da una especie de conexión al que crea con el que observa y con el todo, como si se completara un círculo.

En Alemania existe un pensamiento diferente en donde la filosofía no se mezcla con la estética y además se tiene una ciencia general del arte. La estética alemana "es una combinación de la metafísica tradicional de este país y del esfuerzo de la psicología moderna" (Bayer, 1965, pág. 410). Algunas de las diferentes corrientes de pensamiento alemanas fueron al de Geiger que habla de una estética hedonista en donde la obra es el medio para liberar un placer. Theodor Lipps, con un enfoque más psicológico habla del acto estético como un proceso de identificación del Yo con el no-Yo, es decir una transferencia de sentimientos al objeto que podríamos entender como el vínculo del Yo con el universo del que hablaba Huygue en Francia. Esta teoría de identificación del sujeto en el objeto la podemos ver también en Meumann que habla de la adhesión pasiva del sujeto al objeto. Un punto de vista que me interesó especialmente fue el del alemán Emil Utitz y que desarrolla después Worringer: la idea de la diferenciación entre estética y ciencia del arte para el estudio de todas las manifestaciones, la estética se ocuparía del arte clásico (lo bello) y la ciencia del arte de todas las demás manifestaciones artísticas. Me pareció que sería una forma interesante y novedosa de estudiar al arte, aunque estaría el problema de negar la existencia de la belleza en las manifestaciones artísticas contemporáneas. Otro punto de vista es el del Smarzov, según el cual "la actitud creadora del hombre es una de las maneras de entenderse con el mundo exterior" (Bayer, 1965, pág. 420) y habla de ésta como una teoría de adaptación en la que las leyes de la naturaleza humana son las que la rigen: la simetría que viene de la sensación de nuestros dos brazos y dos ojos, la percepción del eje vertical del cuerpo y el ritmo en el movimiento. Dice que el mundo y el hombre existen el uno para el otro y que esta reciprocidad es la condición fundamental para la creación artística. Me recuerda a una idea del período romántico de que todo lo que existía en el universo a gran escala se repetía infinitamente en escalas menores en nosotros y nuestro alrededor.

Heinrich Wölfflin nos habla de un rechazo a la personalidad del artista, para él la historia del arte debía ser anónima; por otro lado encontramos a Fiedler y la teoría de la "visibilidad pura" que nos dice que el ojo del artista no ve de manera diferente al de cualquiera, sin embargo adquiere un conocimiento en lo que ve. Los artistas usan este conocimiento de lo real y lo plasman en nuevas perspectivas visuales. Entiendo que para Fiedler si era importante el artista, o más bien su personalidad en relación con su estilo y la nueva forma de ver la historia a partir de estas perspectivas, que ya no serían una simple evolución de las formas. En la estética Italiana tenemos a Benedetto Croce que habla del arte como algo intuitivo, que no depende de un concepto o una lógica, lo que lo hace autónomo, "es la intuición del [...] individuo" (Bayer, 1965, pág. 428). A partir de esto, Croce dice que el placer estético para el que ve la obra está en encontrar la intuición del autor, y que esto es lo que debe hacer también el crítico de arte, que debe tratar de ponerse en el lugar del artista y de comprender su obra por intuición. Croce también hace una distinción entre ramas del estudio del arte; por un lado sitúa a la crítica como la que se ocupa de lo que pertenece al campo del arte y por otro a la historia del arte que abarca a la crítica y su papel es descubrir que pertenece al arte y qué no.

También en Italia esta Lionello Venturi quien dice que la estética es histórica y que el valor de la obra no depende del objeto representado, sino del cómo, de la manera que tiene cada artista de representarlo; vemos de nuevo el tema de la personalidad del artista que queda en la obra y de la individualidad de ésta. Luigi Stefanini también nos habla de esto y amplía el concepto de la expresión de Croce; Stefanini dice que entre la obra y el universo está el artista quien le da singularidad a la obra por lo que "la persona debe ser considerada como el principio generador de la obra de arte" (Bayer, 1965, pág. 430). Para este autor la obra tiene vida propia y tanto el autor como la obra tienen un lazo y dependen el uno del otro. Creo que tiene razón de alguna forma, porque al crear algo siempre pones algo de ti en ello, en nuestro caso como estudiantes de arte por ejemplo, aun cuando solo hacemos ejercicios cada quien los hace a su manera y a veces podemos reconocerlos $y$ saber de quién es cada uno con verlos.

En Estados Unidos, a diferencia del resto del mundo en este siglo se le da gran importancia al uso de la técnica en el arte. En el texto Bayer da un ejemplo usando a He- 


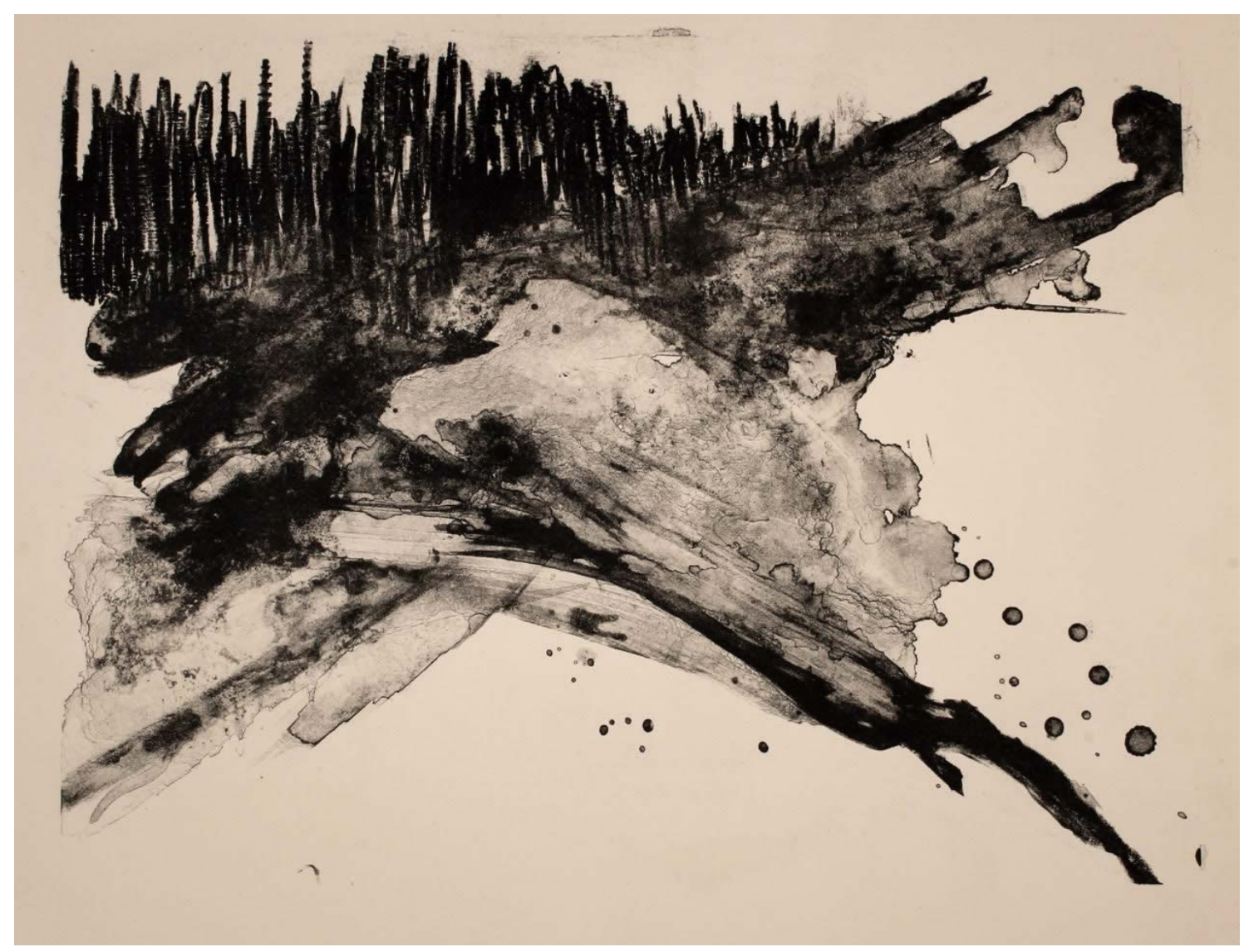

Autor: Adriana Salazar Lamadrid

Título: Complejo A

Técnica: Litografía

Año: 2014

mingway y cómo utilizaba una técnica literaria calculada para dar el efecto de la espontaneidad. Encontramos varias orientaciones en cuanto a estética, está la formalista de Wilenski que le da máxima importancia al volumen, al punto de decir que su creación es la misión del arte; Hungerland nos habla también de la forma y su paralelismo con los estilos del arte, así como la relación entre algunas emociones con ciertos estilos. Los estadounidenses también se interesaron por la sociología y por la estética psicológica que "estudia la obra de arte no solo desde el punto de vista de la forma, sino también desde el ángulo de los factores sensibles y psicológicos" (Bayer, 1965, pág. 458). Munro presenta ideas interesantes al decir que la estética se ha vuelto algo científico y al tratar de que el arte sea parte de la educación para sensibilizar a las personas desde niños; también habla del arte en un aspecto intelectual como lenguaje e instrumento de comunicación y en su aspecto afectivo al expresar el Yo (aquí vemos la presencia de la psicología de nuevo). Para respetar la libertad, según
Munro, debemos aceptar las nuevas formas de arte y la creación libre, habla de tener lo que podría decirse como una actitud científica hacia la observación de lo bello, es decir ser objetivos. Esto es característico de la estética estadounidense que es vista más como una doctrina que se apoya de otras áreas de investigación. Estas ideas son las que me parecen más familiares y fáciles de comprender, creo que por lo mismo de tener un enfoque más técnico y científico es más práctico, además de que parecen más coherentes entre sí al tener una misma base y la relaciono con las vanguardias del siglo en su idea de aceptar los diferentes estilos, es un concepto más abierto a lo que era un arte ya más desarrollado, como sí en vez de tratar de buscarle lo estético a este nuevo mundo de estilos diferentes, sólo se aceptan y se observan como dicen Munro, de manera objetiva. Al mismo tiempo me parece que les falta ese toque sensible que tenían los italianos o los franceses por ejemplo.

En la U.R.S.S. encontramos un mundo completamente opuesto en la que el arte está subordinado a la política y el artista no tiene libertad; es en este siglo cuando esto se empieza a combatir gracias a varios artistas y jóvenes. La doctrina oficial es el realismo socialista, y esto es muy claro en los comentarios que vemos de Jdanov en el texto de Bayer, donde habla de la necesidad de mantener los pies en la tierra para crear arte y de la lucha por la liberación del trabajador del capitalismo. Se repite en este contexto soviético que el arte debe transformar la vida y servir al conocimiento y al mismo tiempo se habla de un espíritu religioso y subjetividad que vuelve todo simbólico; Bulakov habla también sobre el nexo entre arte y religión, y dice 
algo que me parece un aspecto importante al hablar de las vanguardias artísticas del siglo $X X$ y es que reconoce que no todo lo bello es bueno o viceversa.

\section{Conclusión}

Como conclusión puedo decir que no hubo un solo estilo estético en el siglo XX, cada territorio tenía su propia manera de pensar que venía desde antes, como sobre todo en los soviéticos y en los británicos, que no se metieron nada en el aspecto espiritual y prácticamente en la estética tampoco; y creo que esto se debe a que el mundo estuvo en constantes cambios en todo este periodo, si nos ponemos a pensar las cosas nunca habían pasado tan rápido. Todo era fugaz, incluso la velocidad a la que se podía ir de un lado a otro, todo era veloz, el mundo estaba en constante evolución. Además de esto el arte no tenía normas que respetar como en la época clásica y a los artistas ya no les importaba, cada quien se imponía sus propias reglas, sus propios manifiestos de cómo debía ser su arte; puede ser incluso que por eso todas las corrientes duraran tan poco. Algo que leí y que me llamó mucho la atención es que el mundo es relativo. La forma de ver las cosas eran diferentes para cada quien, cada quien veía el mundo a su manera y querían expresar cosas diferentes.

A mí en lo personal me gusta estudiar el pensamiento y contexto histórico de cada corriente artística y este me llama mucho la atención porque se puede ver claramente cada tipo de influencia que hubo en cada forma de proyec- tarlo en una obra de arte, por ejemplo aunque no se representara específicamente el acontecimiento lo veíamos referenciado y podemos ver el impacto que había tenido en la forma de usar los elementos del artista, ya sea poesía, pintura o lo que fuera. La idea ya no era que la imagen se viera bien, que fuera agradable a la vista sino que causase un impacto a quien la viera. De todo lo que leí, lo que más me gustó fue la idea de la conexión que hay entre las cosas, entre la obra, el artista, el espectador y el universo y lo que queda del artista en la obra, creo que esto es algo real aunque suene algo romántico. Es lo que tiene el arte que lo hace bello, creo que eso es para mí la belleza.

Me gustó leer sobre este tema porque me parece interesante ver todos los puntos diferentes que existieron en este punto de la historia, ver cómo fue cambiando la idea de lo que era estético y como era diferente para cada quién o como para algunos realmente no importaba. Otro aspecto que me gusta de este siglo es la integración de las demás disciplinas en el arte, la física y la psicología fueron muy importantes con la teoría de la relatividad que cambió la forma de ver el espacio-tiempo y con los postulados de Freud que integraron el mundo de los sueños al arte. En las teorías de los estéticos de este siglo ví como influyeron mucho en el pensamiento y en sus ideas. Una frase que usa Fleming en su libro cuando habla de las ideas y el arte del siglo XX se me quedó muy grabada: "El cambio es lo único permanente"; creo que a fin de cuentas aunque surjan nuevas ideas y teorías las cosas siempre están cambiando y no va a haber nunca una sola que sea la correcta.

\section{Bibliografía}

Bayer, R. (1965). Historia de la estética. México: Fondo de Cultura Económica.

Bozal, V. (1999). Historia de las ideas estéticas y las teorías artísticas contemporáneas volumen II. España: Visor fotocomposición.

Bozal, V. (2000). Historia de las ideas estéticas y las teorías artísticas contemporáneas volumen I. España: Visor fotocomposición.

Fleming, W. (1971). Arte, música e ideas. México: Mcgrawhill/Interamericana 